ment. Task force members concluded that among the necessary changes is the way family physicians are paid

Thus, a sixth FFM task force was born.

"If you can't create a viable business model for the new model of family medicine, then it's not going to work," said AAFP President Michael Fleming, MD, of Shreveport, La, a member of Task Force 6. "This is not just an academic exercise. The focus is on the realworld practice of medicine."

Task Force 6 comprises not only representatives from within family medicine, but also from paying entities: employers, insurers and the Centers for Medicare \& Medicaid Services.

"The payers agree they must find a way to pay us that values what we do," said Fleming. He predicts the improvements will take place "over a spectrum of about 3 to 5 years."

Discussion of the recommendations has been rampant among e-mail discussion groups and at meetings. Michael Sevilla, MD, of Salem, Ohio, a new physician delegate to the AAFP Congress of Delegates, learned about some of the recommendations at the cluster of AAFP commission-committee meetings in January. Some of his colleagues, fed up with issues of liability and reimbursement, say the project is a "waste of time with recommendations created in an ivory tower and not based in reality," he said.

"Personally, I'm optimistic about the recommendations, but I certainly am sympathetic to physicians who are needing more immediate results," he said.

President Fleming shares that optimism, noting the symbolism of releasing the findings in spring. Spring is not only the season of renewal, but also the season of graduations, he said. "The publishing of this report is just the beginning. The leadership committee's work is at an end, and this is the commencement."

Toni Lapp

AAFP News Department

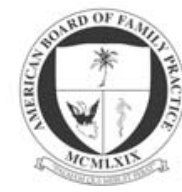

From the American

Board of Family Practice

Ann Fam Med 2004;2:279. DOI: 10.1370/afm.205.

\section{THE JOURNAL OF THE AMERICAN BOARD OF FAMILY PRACTICE (JABFP)}

\section{NEW! Instructions for Authors Updated and Enhanced on JABFP Web Site}

Newly revised instructions for authors are now available at the JABFP Web site at http://www.jabfp.org. While retaining information on the journal's areas of inter- est, several additions have been made to the journal's guidelines. The additions include detailed information on manuscript preparation, conformity with professional standards, and instructions for submitting manuscripts to JABFP — with step-by-step instructions for using Rapid Review. All of these sections have been enhanced with links to mentioned examples embedded in the text.

\section{Rapid Review Update}

Since its launch in March, the Web-based Rapid Review has been available for authors to submit their new manuscripts to JABFP. Authors submitting their first manuscript through Rapid Review must create an author account. Authors must include an e-mail address when creating their account, and they will receive an e-mail confirmation that their manuscript has been received. The JABFP editorial staff will also use e-mail to correspond with authors about the status of their manuscript.

Peer reviewers also enjoy the convenience of Rapid Review. Manuscripts are e-mailed to reviewers, who in turn, send their reviews back via Rapid Review. This eliminates the delays associated with postal mail deliveries.

\section{Looking for a Job? Need to Post a Position?}

The online version of the JABFP's classified ad section is updated immediately as classifieds and other ads are received. Jobs are listed by region and are seen by all. Links to the contact person and/or organization are provided when listed by the advertiser.

Victoria Neale, $\mathrm{PbD}, \mathrm{MPH}$

Deputy Editor, JABFP

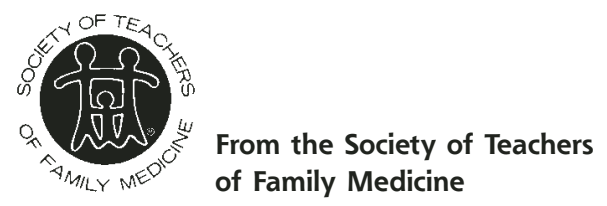

Ann Fam Med 2004;2:279-280. DOI: 10.1370/afm.206.

\section{STFM OFFERS TRAINING AND EDUCA- TIONAL RESOURCES FOR PRECEPTORS}

The Society of Teachers of Family Medicine (STFM), a leader in family medicine education, offers educational resources for volunteer preceptors who teach medical students and residents. Highlighted below are the tools to help community preceptors be better teachers.

\section{Preceptor Education Project Curricular Materials}

The STFM Preceptor Education Project (PEP2) is a faculty development workshop curriculum for family physician preceptors who teach clinical medical students. PEP2 educational materials prepare family physicians to teach medical students effectively and efficiently 